\title{
Urgences
}

\section{Les sexes masqués}

\section{Claire Bienvenue}

Numéro 14, août 1986

Corps et jouissances

URI : https://id.erudit.org/iderudit/025259ar

DOI : https://doi.org/10.7202/025259ar

Aller au sommaire du numéro

Éditeur(s)

Urgences

ISSN

0226-9554 (imprimé)

1927-3924 (numérique)

Découvrir la revue

Citer ce document

Bienvenue, C. (1986). Les sexes masqués. Urgences, (14), 19-23.

https://doi.org/10.7202/025259ar

Ce document est protégé par la loi sur le droit d'auteur. L'utilisation des services d'Érudit (y compris la reproduction) est assujettie à sa politique d'utilisation que vous pouvez consulter en ligne.

https://apropos.erudit.org/fr/usagers/politique-dutilisation/
Cet article est diffusé et préservé par Érudit.

Érudit est un consortium interuniversitaire sans but lucratif composé de l'Université de Montréal, l'Université Laval et l'Université du Québec à Montréal. Il a pour mission la promotion et la valorisation de la recherche. https://www.erudit.org/fr/ 


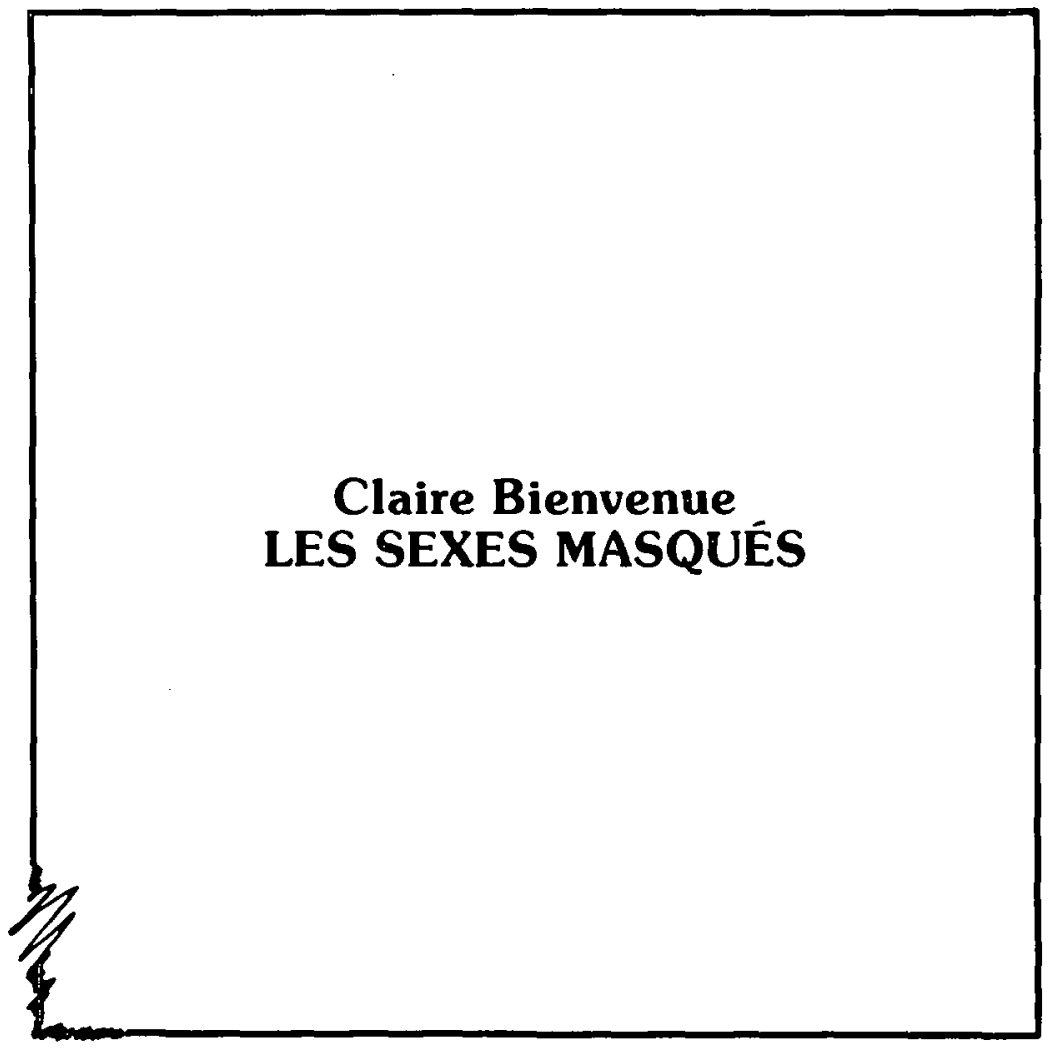


Ce soir, elle est Imogène, expliqua-t-il. Et demain soir, elle sera Juliette.

- Quand donc est-elle Sibyl Vane? - Jamais.

Pleurez, tant qu'il vous plaît, sur la triste Ophélie. On a étranglé Cordélia: couvrez-vous les cheveux de cendres. Maudissez le Ciel, puisque la fille de Brabantio n'est plus. Mais ne gaspillez pas vos larmes sur Sibyl Vane. Elle était moins réelle que ces fantômes.

[...] je vous aimais parce que vous incarniez les rêves des grands poètes et prêtiez un corps et un visage aux fantômes éthérés de l'Art [...]. Désormais vous n'êtes plus rien pour moi.

\section{Oscar Wilde, Le portrait de Dorian Gray}

Sibyl Vane, comédienne, ignore tout de la vie, de l'amour. Elle "joue", en incarnant chaque soir un personnage shakespearien. Sa rencontre avec Dorian Gray transforme sa vision du monde. Elle refuse dorénavant de "faire semblant". Confrontée à la perte de son amoureux elle ne pourra supporter la réalité...

Elle s'apparente ainsi à Ophélie, cette femme née de la plume de Shakespeare, et qui ne cesse, depuis quatre cents ans, de hanter la mémoire des poètes, écrivains, peintres et musiciens. Ophélie demeure une figure à jamais vivante "glissant indéfiniment sur le miroir de la poésie ${ }^{\mathrm{l}}$.

Je tenterai ici de mieux cerner cette "Ophélie jamais noyée (...) joyaux intact sous le désastre ${ }^{2 "}$, Ophélie et ses soeurs Sappho, Antigone, Ondine ou Sibyl Vane...

Dans une mise en scène signée Polonius, l'Ophélie de Shakespeare accepte de jouer, de faire semblant. Les Polonides mâles veillent sur sa chasteté si précieuse et se pensent en droit de décider ce qui sied à son honneur. Attentive aux conseils de tous et chacun, elle fait ce qu'on lui dicte, sans poser de questions. Elle présente d'abord l'image de la jeune fille frêle, naïve, démunie, qui ne pense pas par elle-même. Limpide, elle n'a rien à cacher. Obéissante, on l'utilise comme une marionnette sous le joug du père. Elle ignore les conséquences de son jeu vis-à-vis de celui qui dit l'aimer. Elle se contente 
d'obéir. Ophélie n'a jamais eu à choisir. Même en amour, elle est une "ondine" qui pourrait dire, telle l'Ondine de Jean Giraudoux:

Je ne savais pas que l'on choisit chez les hommes. Chez nous l'on ne choisit pas, de grands sentiments nous choisissent, et le premier ondin venu est pour toujours le seul ondin. Hans est le premier homme que jai vu, on ne peut choisir davantage ${ }^{3}$.

Ophélie ne se pose pas les grandes questions d'Hamlet, elle n'a pas ses angoisses métaphysiques. Elle sent plus qu'elle ne pense:

Elle est incapable de comprendre Hamlet et sa folle quête de la vérité parce qu'elle n'a jamais eu. elle, à chercher sa vérité: elle la possédait d'emblée dans sa perfection".

Rejetée par Hamlet, pour quiles femmes ne sont que "comédiennes" ou "putains", pour qui la chair devient objet de dégoût et de haine, elle ne saura tolérer le monde tel qu'il se présente à elle:

Ainsi. quoi que fasse la fermme, elle ne peut montrer que sa fragilité. Si elle suit la voix de la sensualité. son impossibilité à se contenir témoigne de sa nature bestiale. si elle se réserve pour une union approuvée par la morale, elle cède devant l'autorité paternelle et renie son objet d'amour'

Il faut la mort du père pour qu'Ophélie ose s'affirmer et être elle-même pour la première fois, débordante de paroles, de désirs, de lucidité. Telle l'Antigone d'Anouilh, elle refuse de jouer sa vie et préfère vivre sa mort: "Moi, je peux dire "non" encore à tout ce que je n'aime pas et je suis seule juge"." Trop blanches, trop pures, ces femmes ne peuvent vivre dans un monde d'apparence où tout n'est que tricherie: elles veulent tout, tout de suite - et que ce soit entier-. ou alors elles refusent! "Le tragique en elle(s), c'est justement cette perfection qui ne peut supporter aucune flétrissure ${ }^{3 "}$.

Ophélie va se survivre, un moment, dans la folie. Hamlet choisit de "simuler" la folie; on le croira fou. Ophélie "devient" folle:

C'est la façon qu'ont les hommes de s'en tirer, quand ils ont heurté une vérité. une simplicité, un trésor [...] lis deviennent ce qu'ils appellent fous. Ils sont soudain logiques, ils nabdiquent plus, ils n'épousent pas celle qu'ils n'aiment pas. ils ont le raisonnement des plantes, des eaux. de Dieu: ils sont fous". 
Telle Sappho, Ophélie chante ses amours rêvées et perdues. Ses paroles inquiètent: "ceux qui l'écoutent sont enclins à chercher dans ses mots décousus une logique [...]. Et ces gestes font croire à un sens cachég"'. Elle dérange. Et son entourage préfère l'ignorer ou tenter de la diminuer. On ne cherche pas à comprendre... Rimbaud lui-même, plus de deux cents ans après Shakespeare, semble reporter dans un futur lointain le temps où l'on saura donner à la femme sa place dans un monde fait à son image:

Quand sera brisé l'infini servage de la femme, quand elle vivra pour elle et par elle, l'homme - jusqu'ici abominable - lui ayant donné son renvoi, elle sera poète, elle aussi! La femme trouvera de l'inconnu! Ses mondes différeront-ils des nôtres? Elle trouvera des choses étranges, insondables, repoussantes. délicieuses; nous les prendrons, nous les comprendrons $^{10}$.

N'étant pas de ce monde, Ophélie retournera à son élément, l'eau:

[...] trop entière pour pouvoir faire la part du mal et se révéler d'une quelconque déchéance, sitôt blessée, il lui faudra s'anéantir pour rétablir, au-delà de son sacrifice, l'image de son absolu"l.

Il en est ainsi de ses "soeurs", Sibyl Vane, Antigone ou Sappho... Sibyl s'en va, dès sa première rencontre avec la réalité qu'elle ne peut supporter:

Peut-être pourrais-je jouer une passion dont j'ignorerais le trouble, mais je ne puis jouer celle qui me brûle de tous ses feux ${ }^{12}$.

Pour Antigone tout est trop laid, Créon aurait été obligé de la condamner à vivre:

Aucun de nous n'étions assez fort pour la décider à viure. (...) Antigone était faite pour être morte ${ }^{1 . t}$.

Sappho se suicide par amour. Elle trouve dans la mort la libération de sa peine, de son désespoir et de la cruauté du destin:

[...] consciente de son destin qui la voue à rester parmi les êtres supérieurs, Sappho se précipite du haut du rocher dans la mer tumultueuse ${ }^{14}$. 
Mais, même dans la mort, il semble qu'«Elles» continuent à vivre et à faire rêver les poètes:

Toutes ces femmes

derrière le masque

ont-elles un sexe

de solitude me direz-vous

1 Julien Eymard: "Ophélie ou la naissance d'un mythe", Littêratures, vol. XXIII, 1976, p. 83.

2 Stéphane Mallarmé: Igitur, Divagations, Un coup de dés, Paris, coll "Poésie/Gallimard", 1976, p. 190.

3 Jean Giraudoux: Ondine, Paris, Grasset, 1939. p. 122.

4 Laffont-Bompiani: Dictionnaire des personnages de tous les temps et de tous les pays. Paris, Laffont. 1960 . p. $730-731$.

5 André Green: Hamlet et Hamlet, Paris. Balland, 1982, p. 68.

6 Jean Anouilh: Antigone. Paris, Ed. de la Table Ronde. 1947. p. 84

7 Laffont-Bompiani: Dictionnaire des personnages..., p. 730 .

8 Jean Giroudoux: Ondine..., p. 183

9 William Shakespeare: Hamlet, Paris, coll. "Le livre de poche", no 1265-1266, 1959, p. 128.

10 Arthur Rimbaud: Poésies complètes. Une saison en enfer, Illuminations et autres textes. Paris. Gallimard. 1960. p. 221-222.

11 Laffont-Bompiani: Dictionnaire des personnages..., p. 731.

12 Oscar Wilde: Le portrait de Dorian Gray, Paris, coll. "Le livre de poche" , no. 569, 1980. p. 112.

13 Jean Anouilh: Antigone..., p. 107.

14 Laffont-Bompiani: Dictionnaire des personnages..., p. 883. 